\title{
Long-Term Care: Risk Description of a Spanish Portfolio and Economic Analysis of the Timing of Insurance Purchase
}

\author{
Montserrat Guillén ${ }^{\mathrm{a}}$ and Jean Pinquet ${ }^{\mathrm{b}}$ \\ a Department Econometria, Estadística i Economia Espanyola, RFA-IREA, University of Barcelona, \\ Diagonal, 690, Barcelona 08034, Spain. \\ E-mail: mguillen@ub.edu \\ ${ }^{\mathrm{b}}$ Ecole Polytechnique, Département d'Economie, Palaiseau 91128, France. \\ E-mail: jean.pinquet@polytechnique.edu
}

This paper analyses the rationale of long-term care (LTC) insurance purchasing from a statistical analysis of insurance data and a life cycle model. We make a short survey of the pros and cons of LTC insurance purchase. Then risk distributions in the occurrence and duration dimension are estimated on a Spanish portfolio. Calendar effects are estimated besides age and gender. These statistical results are integrated in a life cycle model of savings and insurance purchasing. A numerical illustration is also provided, which leads to an optimal age of 40 years for insurance purchase.

The Geneva Papers (2008) 33, 659-672. doi:10.1057/gpp.2008.33

Keywords: long-term care insurance; Lee-Carter models; life cycle approach; calendar; gender and age effects

\section{Introduction}

The continuous ageing of the population in developed countries creates a need for long-term care (LTC) services. These services provide assistance to individuals subject to old-age dependency. They are often termed community care and are a substitute to the care giving traditionally provided by the family and neighbours of the dependent individual. In southern European countries, the role of community care is still incipient as compared to Northern Europe. A 2005 survey shows that Spanish families provide care for 69 per cent of the non-institutionalised population. ${ }^{1}$ In the United Kingdom, the corresponding percentage is equal to 32 . This disparity can be explained by a wider spread of community care in the U.K. However, in Spain, the number of older people that live alone or with a partial informal support system (either due to the death of a spouse or to a limited number of children) is increasing. Therefore, the risk that they will need assistance or residential services is escalating if informal care substitutes for formal care. A study on the Health and Retirement Survey shows that informal care substitutes indeed for formal care, as regards nursing home use, home

\footnotetext{
${ }^{1}$ Costa-Font and Font-Vilalta (2006).
} 
660

health care use, inpatient care and physician visits. On the other hand, complementarity is observed for outpatient surgery. ${ }^{2}$

In 2006, the Spanish Government instituted a law to promote personal autonomy and care for persons in a situation of dependency (Ley de Promoción de la Autonomía Personal y Atención a las Personas en Situación de Dependencia). This law was designed to function as the "fourth pillar" of the welfare system at all coverage levels, but during 2007 only those having the highest degree of severity received public subsidies. The system is financed by public funding at the state, regional and local level. It is not based on a compulsory contribution as in Germany and the benefits are first provided on the basis of a severity score. In the case of the highest severity of impairment, eligibility is based only on that severity score. If the level of severity is lower, eligibility is determined also on the basis of income and wealth. Owing to the high costs of LTC, it became obvious shortly after the system had been implemented that the overall cost of the coverage was much higher than predicted by the law. One can argue that due to a strong marketing campaign by the government, most individuals initially believed that the public system would cover all LTC needs, but the Spanish public system is designed as a social right in very acute situations.

In this context, most insurers claim to be prepared to launch LTC products for the Spanish market but actually only a few of them really offer this type of insurance. The reason put forward is the lack of demand. As a consequence, insurers have insisted that LTC products must be tax qualified in order to be attractive to consumers. The recently approved tax regulation permits a deduction of the premiums paid to LTC insurance for severe and total dependence (up to $€ 12,500$ per year) from income for fiscal purposes. Unfortunately, at this point, most individuals are confused by the changing regulations and do not know exactly what their legal rights are with respect to public LTC coverage and what private insurance can really offer.

There are two polar insurance markets for private LTC insurance. The French market provides fixed indemnity coverage in the form of monthly annuity payments. On the contrary, the American market operates on the basis of reimbursement models. The American model is subject to escalating costs, especially through court decisions and a moral hazard effect. ${ }^{3}$ However, a reimbursement insurance contract provides a better hedging of risks. The Spanish market is developing along the lines similar to those retained in France. We will implicitly refer to this type of insurance product in risk assessment and in the economic analysis of insurance demand. Hence the components of LTC risk assessed in the paper are the occurrence and the duration of the LTC spell, but not the severity of impairment and its financial consequences. We summarise the pros and cons of LTC insurance purchase in the next section. Then we present a statistical analysis of a Spanish portfolio of permanent disability insurance contracts sold by a mutual insurance company. They include LTC for the elderly, and we describe both the occurrence risk of an irreversible disability state, and the duration in this state. Our statistical study includes an analysis of calendar effects.

\footnotetext{
${ }^{2}$ Van Houtven and Norton (2004). On European data, complementarity is also obtained for physician visits (Bolin et al., 2008).

${ }^{3}$ See Kessler (2008) for more developments.
} 
In the section "Life cycle analysis of ex ante LTC insurance demand," we integrate our statistical results into an economic model of optimal insurance purchasing in order to question the timing of LTC insurance purchase during a lifetime. We use an extension of Yaari's life cycle model, ${ }^{4}$ with the addition of an irreversible disability state. We present a numerical illustration of the model in which the optimal age of purchase is about 40 years. We also perform a sensitivity analysis of the consumer's behaviour with respect to the main parameters of the life cycle model. We discuss the limits of our approach (selection bias issues as insurance demand is assessed from a portfolio of policies, connections with usual insurance demand models). Lastly, we draw conclusions and clarify our future research directions. Technicalities are relegated to an Appendix. ${ }^{5}$

\section{The pros and cons of LTC insurance purchase}

Let us detail the arguments in favour of LTC insurance purchase. Some of them are derived from a risk analysis of LTC. There are two components in LTC risk. The first component is the occurrence risk of facing an LTC spell during the life cycle, and the second is the duration risk in the LTC state (together with the severity of impairment). A decrease in the occurrence probability of an LTC spell should be followed by a similar variation of the price of LTC insurance and make insurance purchase less deterred by potential losses due to lapses. Indeed, an LTC contract is a very illiquid asset, which is usually not or only partially repaid in case of surrender. The probability of using the coverage on the life cycle strongly depends on the contract type. A fixed indemnity coverage only insures irreversible LTC spells, as the policyholder receives an annuity. The probability of facing an LTC spell during the life cycle is close to 10 per cent on our data for the representative consumer retained in our life cycle analysis (a man, born in 1950). When insurance contracts follow a reimbursement model, they usually cover reversible dependence risk and the aforementioned probability often exceeds 25 per cent. Because of risk aversion, the willingness to buy LTC coverage increases with the expected duration of LTC and with the heterogeneity of duration distributions. Besides, an overestimation of risks is often observed for low frequencies and increases the motivation to insure. ${ }^{6}$ Individuals who engage in more preventive health activities tend to systematically overestimate the probability of a dependence spell. ${ }^{7}$ In this respect, LTC risk could be a source of "advantageous selection," at least for young buyers of insurance. This means that insurance purchase might send a positive signal on the risk level, a result opposite to the usual "adverse selection" effect. $^{8}$ Lastly, the motivation to buy LTC coverage increases with bequest motives.

\footnotetext{
${ }^{4}$ Yaari (1965).

5 Available at http://ceco.polytechnique.fr/publications/ (working paper 2008-03).

${ }^{6}$ Kunreuther et al. (1978).

${ }^{7}$ Finkelstein and McGarry (2006).

${ }^{8}$ See De Meza and Webb (2001) for an economic analysis of "advantageous selection," and Fang et al. (2008) for econometric developments on adverse vs. advantageous selection on the Medigap insurance market in the U.S.A.
} 
The first argument against the purchase of LTC insurance is the crowding out effect by public insurance. In Germany, for instance, a fifth pillar of the social security system was created in 1995 and it leaves little room for private insurance. ${ }^{9}$ A high loading factor for LTC insurance may also deter potential buyers. As statistical study of American contracts quotes an average value of 0.18 if the policy is held until death, whereas the loading factor rises to 0.51 if we account for lapses. ${ }^{10}$ The presence of children can work in two ways. On the one hand, it creates bequest motives and a motivation to buy insurance coverage. On the other hand, the elderly may fear that, if they purchase insurance, children may institutionalise them when they are unable to act on their own. Therefore, an elderly person who prefers attention from children over purchased help may decide not to buy LTC insurance. ${ }^{11}$ Another reason not to buy LTC insurance is the lower utility of consumption in a poor health state. ${ }^{12}$

Other problems arise besides the insurance purchasing choice. The first is the optimal date of purchasing. Indeed, there is an irreversibility issue: the insurance contract often cannot be repaid before entry into the LTC state. Hence, there is a timing decision that must be made as in any real options issue. Second, there is an alternative solution to ex ante insurance, which consists in buying annuities once the LTC state is reached. Several products of this type are proposed, which are termed immediate annuities, reverse mortgages, etc. The wealth effect on the willingness to buy LTC insurance is not straightforward. On the one hand, the deterrence effect of repayment risk should decrease with income and wealth. Besides, bequest motives increase with wealth and motivate the hedging of LTC risk. On the other hand, the motivation to use immediate annuities as a substitute for ex ante insurance (i.e., to self-insure against occurrence risk) increases with wealth. For instance, home equity can be sold in return for a life annuity, should an LTC spell occur. ${ }^{13}$

\section{Statistical analysis of a Spanish database}

\section{Presentation of the database}

In Spain some insurers have sold LTC coverage for many years as an extension to permanent disability insurance. Individuals who claim not to be able to perform daily life activities receive an annuity, even if they are already retired. The data analysed here comes from a sample of contracts drawn at random from a mutual insurance company. We have 150,000 insurance contracts and 2,800 LTC spells in round figures. The information was collected for 30 years, which allows us to study calendar effects from 1975 to 2005 . The file contains all the available data for policyholders having underwritten the same product. The product is a disability coverage that provides a

\footnotetext{
${ }^{9}$ See Taleyson (2003) for a survey of the LTC insurance market along with public financing of LTC in the world.

${ }^{10}$ Brown and Finkelstein (2007).

${ }^{11}$ See Sloan and Norton (1997) for further developments and an empirical study on the AHEAD and HRS databases.

12 Pauly (1990).

13 Davidoff (2008).
} 
monthly compensation when a person is declared disabled. The state of disability is assessed by doctors appointed by the company on the basis of standard medical and physical tests. Disability is equivalent to a severe dependence level, where the individual is not able to perform daily life activities without the assistance of another person. Conditions to become eligible are very strict. In the contract they are defined as "a permanent and irreversible loss of the capacity to function autonomously due to: irreversible psychotic disorder, hemiplegia, paraplegia, severe Parkinson's disorder, aphasia or Wernicke disorder, or dementia due to cerebral malfunction." In addition, due to traditional practices in companies, blindness or losing two arms or legs are sufficient conditions to grant compensation.

The insurance product analysed here can be understood as an LTC insurance that complements permanent disability coverage. It was very popular in the 1960 s and 1970s, mainly due to the disability coverage and to the weakness of public pensions at that time. A striking result is the age of policyholders at the inception of the insurance contract, which is only 28 years, and it increases with calendar time. An explanation is that this coverage was sold in tandem with a temporary disability policy, which could be used earlier in the life cycle by the policyholders. An explanation is that the policyholders first hedged permanent disability risk in a context where the public coverage was very weak. Usually buyers of LTC insurance are middle aged or are young retirees. In France, the age of LTC insurance purchasers decreased from 65 to 61 years on average in a few years. The application of a life cycle approach given later in the paper shows however that rather young adults may rationally opt for LTC coverage.

\section{Statistical results}

Duration distributions of LTC spells

Table 1 presents the estimation of a proportional hazards model on the duration of LTC spells. Covariates are the age at the beginning of the LTC spell, the corresponding date in order to allow for a calendar effect and the gender. The individuals are the LTC spells and the dependent variable is the pair duration - event indicator. The event is death (1,868 deaths out of 2,787 LTC spells), which is the only possible exit from LTC in our setting. Dependent policyholders who are still alive at the date of data gathering generate a censored observation.

The proportional hazards model estimates a death rate for individuals in LTC, where the specification of the instantaneous death rate of the policyholder $i$ is

$$
\lambda_{i}(t)=\exp \left(\alpha_{1}\left(x_{1}\right)_{i}+\alpha_{2}\left(x_{2}\right)_{i}+\alpha_{3}\left(x_{3}\right)_{i}\right) \times h(t) .
$$

The duration $t$ is the seniority of the policyholder in the LTC state.

Table 1 Proportional hazards model for the duration of LTC

\begin{tabular}{lcc}
\hline Covariates & Estimated coefficient & Estimated standard deviation \\
\hline$x_{1}$ : Age at the beginning of the LTC spell & 0.0558 & 0.00248 \\
$x_{2}:$ Date at the beginning of the LTC spell & 0.0788 & 0.00499 \\
$x_{3}$ : Indicator of female gender & -0.325 & 0.166 \\
\hline
\end{tabular}


Ceteris paribus, a supplementary year of age increases the mortality rate of 5.7 per cent, and a supplementary calendar year is associated with an 8.2 per cent increase. ${ }^{14}$ This second result denotes a decreasing trend in the duration of LTC. Women also stay longer than men in LTC. The estimated instantaneous death rate for the average characteristics $\left(\overline{x_{1}}=70.8\right.$ years; $\left.\overline{x_{2}}=1997.4 ; \overline{x_{3}}=5.4 \%\right)$ is roughly equal to 0.13 , with a slightly increasing shape as a function of seniority. This means that the death rate per year in this case is close to 0.12 . This death rate is the average for 84-year-old men in Spain in 1997, and for 88-year-old women, regardless of their state of health. Entering in an LTC state strongly increases mortality for the elderly, but the relative variation decreases with age and with the seniority in LTC.

\section{Occurrence risk of entry in an LTC spell}

The purpose of this section is to analyse the occurrence rate of entry in an LTC spell, depending on the age and calendar time. We did not introduce gender because women represent only 5 per cent of LTC spells and their sample is too small for a regressionbased estimation. The relative risk exposure associated with women is equal to 20 per cent if measured by the duration, and to 7 per cent if the age and calendar time are controlled for in the model estimated hereafter. About 150,000 policies are considered in the analysis, but there are almost 60,000 lapses in the sample. The portfolio reached a peak of 90,000 policies in 1992, then it was closed because LTC and permanent disability insurance contracts were redefined for new business. There were 55,000 policies remaining in 2005 .

The number of entries in LTC for a given age and calendar year is compared to the risk exposure. As we have many zeroes for these numbers but also for risk exposure, we did not perform a direct analysis of the entry rates, as in a Lee-Carter approach. We retained a binomial model and a specification of the hazard rate that is that of LeeCarter. Let $n e_{t, x}$ be the number of entries in LTC during the year $t$ at the age $x$, where $t$ and $x$ have integer values. If $n g h_{t, x}$ is the corresponding number of policyholders in good health (i.e. the risk exposure), the binomial model is the following

$$
\begin{aligned}
N E_{t, x} & \sim B\left(n g h_{t, x}, p_{t, x}\right) ; \quad p_{t, x}=1-\exp \left(-\lambda_{t, x}\right) ; \\
\lambda_{t, x} & =\exp \left(a_{x}+c_{t} u_{x}\right) .
\end{aligned}
$$

The vectors $a, c$ and $u$ represent respectively an average age effect, a calendar effect and a multiplier applied to the calendar effect. For instance, consider two different calendar dates $t_{1}$ and $t_{2}$, and a given age $x$. The ratio between the corresponding hazard rates is equal to

$$
\frac{\lambda_{t_{2}, x}}{\lambda_{t_{1}, x}}=\exp \left(\left(c_{t_{2}}-c_{t_{1}}\right) \times u_{x}\right) .
$$

The last expression leads to an interpretation of $u$ as a multiplier on calendar effects. ${ }^{15}$

\footnotetext{
${ }^{14}$ This calendar effect is too high to be used for plausible long run predictions. Taking into account subintervals of calendar time in the estimation leads to rather chaotic results.

15 The Lee-Carter (1992) model performs a Principal Component Analysis (PCA) on the logarithms of entry rates, which are most often death rates. The vectors $a, c$ and $u$ are respectively the averages of logrates by age, the principal components and the principal factors of the PCA.
} 


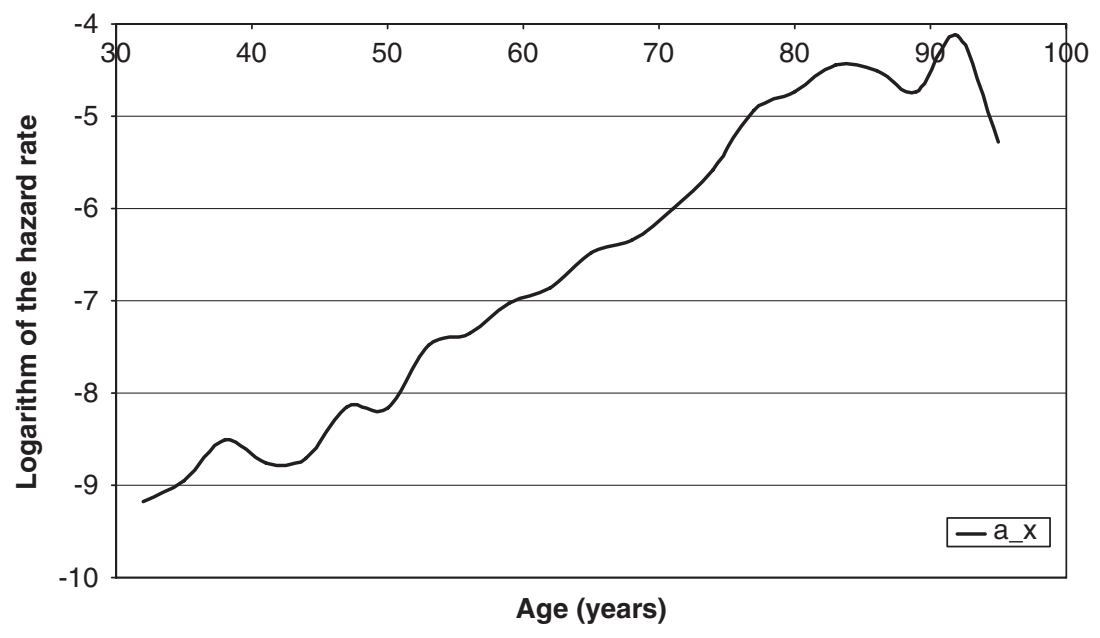

Figure 1. Average effect of the age on the entry rate into LTC.

Identifying constraints are required for $c$ and $u$. In a Lee-Carter approach, the principal components $c$ are centred and the norm of the principal factor $u$ is equal to one. We retained these constraints here with weights proportional to the number of entries. ${ }^{16}$ The model needs strictly positive margins on the number of entries in order to be estimated. We restricted the calendar time interval from year 1975 to 2005, and age from 30 to 95 years. The first seven calendar years are gathered in a single observation, due to low values for the number of entries in LTC spells at the beginning. The age levels are 3-year intervals. Hence we have 25 calendar levels and 22 age levels in the estimation. The estimation of the average effect $a$ is given in Figure 1. The growth rate with respect to age of the entry rate into LTC is almost constant and close to 10 per cent. This result is close to what is usually observed for death rates (growth equal to 8-9 per cent per year for most of the life cycle). The ratio between the entry rate into LTC and the death rate is close to 0.1 for the consumer retained in the next section (a man, born in 1950), and the same result holds for the probability of facing an LTC spell before dying.

The average entry rate into LTC increases quickly with calendar time in the portfolio, but this growth partly disappears if age is controlled for, as in this model. Figure 2 exhibits almost constant values for $c_{t}$ during the last 10 years. The coherence with the preceding result is due to the constant ageing of policyholders in the portfolio. There is however a sharp increase in the entry rate in 1992 and 1993. The insurance company modified its rating structure at that time and this calendar effect could reflect a simultaneous slackening of acceptance rules for LTC spells.

\footnotetext{
${ }^{16}$ This choice was made from a local expansion of the log-likelihood of the binomial model, interpreted as a Euclidean distance between theoretical and empirical frequencies. Anyway, the estimated hazard function does not depend on the identifying constraints.
} 


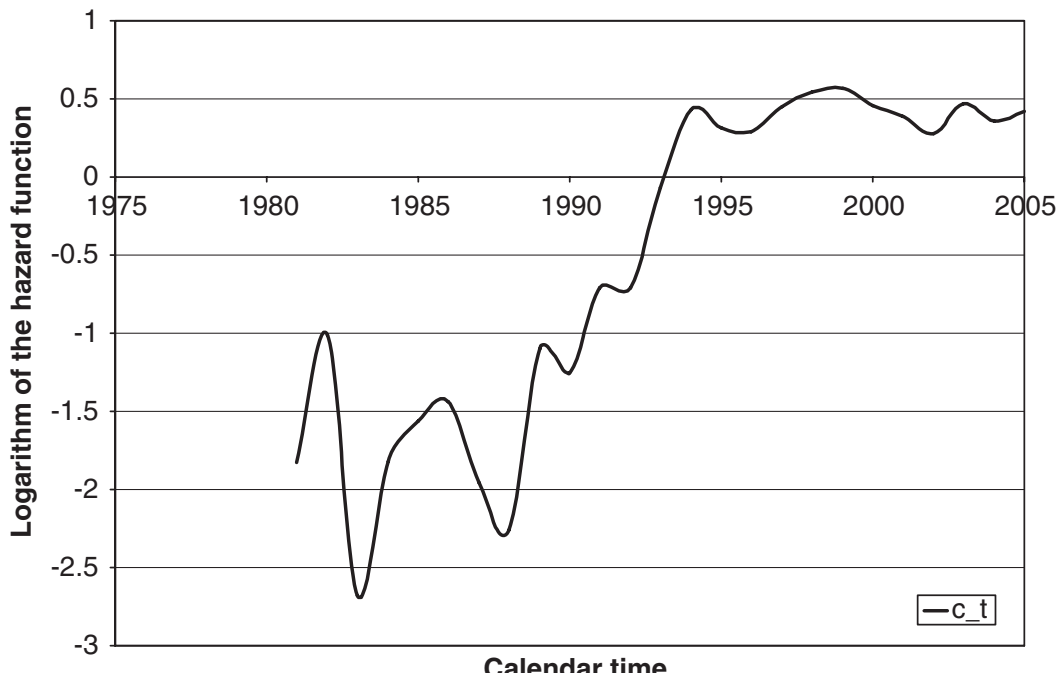

Figure 2. Effect of calendar time on the entry rate into LTC.

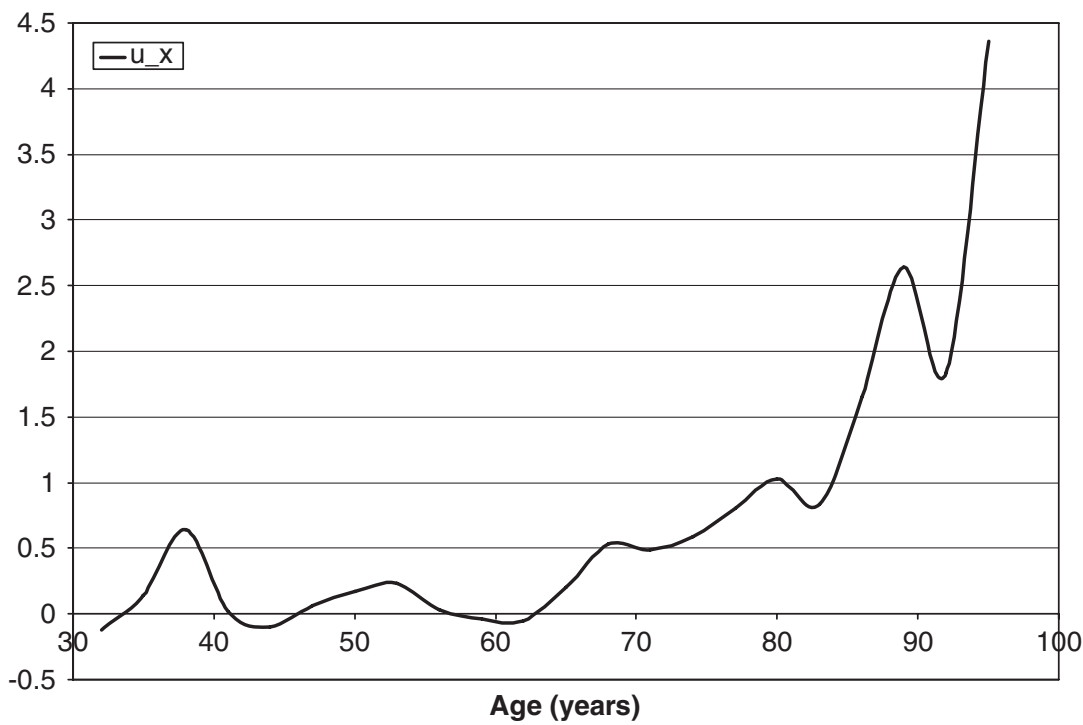

Figure 3. Multiplier effect of the age on the calendar time effect.

The multiplier $u$ increases beyond 60 years of age (see Figure 3). The increase of the entry rates in LTC observed before 1995 in Figure 2 is only effective beyond 60 years. 


\section{Life cycle analysis of ex ante LTC insurance demand}

A life cycle analysis of the consumer is the suitable framework to analyse the timing of LTC insurance purchase. In this section, we present an extension of Yaari's model. Yaari's paper is seminal for the life cycle analysis of consumption and savings with life duration risk. It complements the fixed horizon models, where randomness is considered at the income and asset return levels. ${ }^{17}$ The rationale for LTC insurance purchase can also be studied in the Merton-Samuelson framework. Gupta and $\mathrm{Li}^{18}$ follow this approach (the planning horizon is retirement), with a stochastic model on the health capital and also departures from the expected utility model. Our model starts from Yaari's specification and includes LTC insurance bought ex ante in a model where irreversible dependency is a possible transition between a good health state and death. Adverse selection is low for young buyers of LTC insurance (for which we might even have an "advantageous selection" effect), as discussed in the above section on the pros and cons of LTC insurance purchase. Our approach, which applies on LTC insurance demand statistical results that are derived from LTC policies should not create an important selection bias. Using the statistical estimations of the preceding section, we will give a numerical example of optimal insurance purchase and savings behaviour in this context.

Figure 4 shows the life cycle evolution of a consumer's optimal consumption and wealth under the following assumptions.

- The income flow is also given in Figure 4. It increases from 25 to 50 years and then decreases until the age of retirement (65 years). The retirement income is constant and equal to 60 per cent of the maximum wage. The wealth at age 25 is equal to zero.

- The utility of consumption $u$ is a (constant relative risk aversion) CRRA function. The relative risk aversion coefficient is equal to 2 , and we retained $u(c)=-1 / c$. The CRRA utility function is retained first because the marginal propensity to consume is infinite in zero, which rules out a null consumption at the optimum. In that case, the life cycle model is restricted to the time interval where income is strictly positive. This result simplifies the interpretation of the Euler equation on the optimal consumption path. The Euler equation is fulfilled when positivity constraints on wealth and consumption are not binding. With a CRRA function, this means that wealth is greater than zero. Economic studies state that a relative risk aversion coefficient should range between 1 and 4 for most of the consumers. ${ }^{19}$

- The utility of bequests (depending on the date of death and on the wealth bequeathed) is obtained from a hump-shaped function of time and from an increasing and concave function of wealth. A plausible optimal wealth path implies that the marginal utility of consumption exceeds the marginal utility of bequests if the wealth is large enough.

\footnotetext{
${ }^{17}$ Merton (1969) and Samuelson (1969).

${ }^{18}$ Gupta and Li (2007).

${ }^{19}$ Barsky et al. (1997) and Gollier (2001).
} 


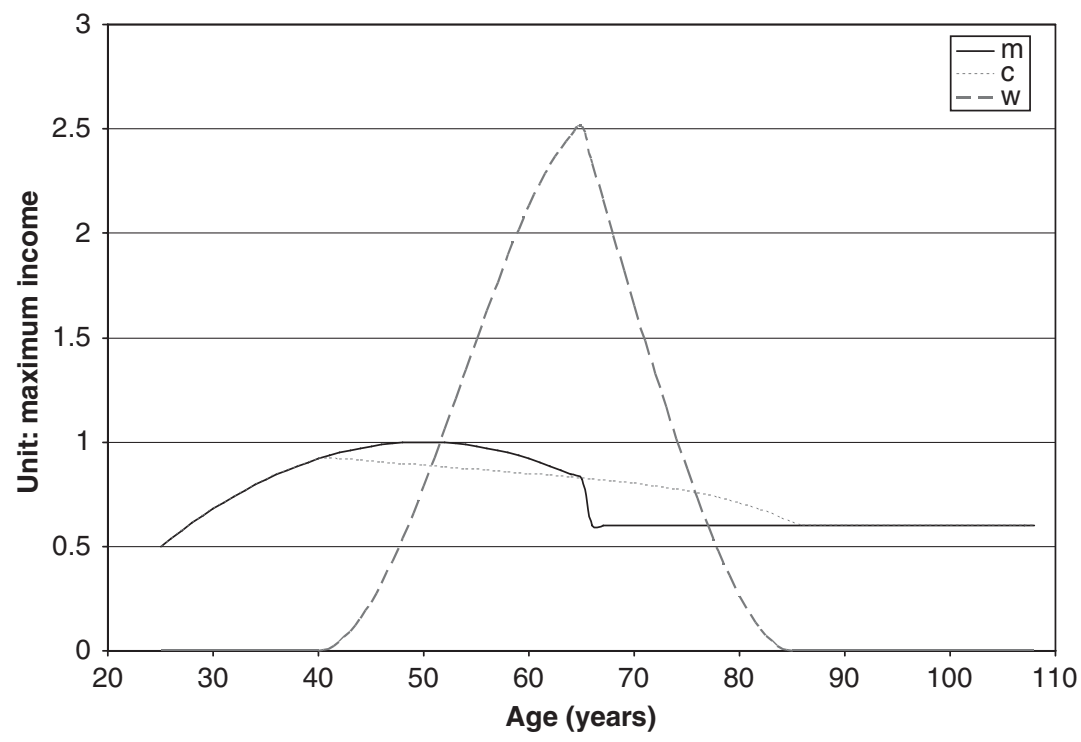

Figure 4. Life cycle evolution of income $(m)$, consumption $(c)$ and wealth $(w)$.

- The real interest rate is equal to 2 per cent, and the subjective discount rate is equal to 3 per cent.

- Lastly, the mortality rates are estimated and predicted from Spanish data at the national level. We estimated a Lee-Carter model on mortality rates drawn from the Human Mortality Database. ${ }^{20}$ Mortality rates for individuals in good health are then estimated for each gender in order to make the national mortality rates consistent with our statistical results on LTC. The consumer is assumed to be a man, born in 1950 .

From Figure 4, we see that the consumer begins to save at age 41 . The wealth reaches a peak at the age of retirement, and then decreases until age 84 . The downturn of wealth at the age of retirement is due to the continuity of the optimal consumption path. Hence the decrease in savings compensates the drop in income at that date. At the end of the life cycle, there is no bequest left to the heirs. The last result is unavoidable in Yaari's model under fairly general conditions. ${ }^{21}$

Usual LTC insurance is bought ex ante, that is, when the policyholder is in good health. The policy covers both an occurrence and a duration risk. Other LTC insurance products are immediate annuities that are bought when the policyholder has reached the LTC state. In that case only the duration risk is covered.

Let us include ex ante LTC insurance in this life cycle model. We suppose that the coverage can be bought only once in a lifetime, and that the insurance contract cannot

\footnotetext{
${ }^{20}$ Available at http://www.mortality.org/.

21 The original proof is due to Leung (1994).
} 
be repaid. Three states of health are defined (good health, irreversible dependency and death). The purchase occurs only in the good health state, and the premium is paid continuously until this state is left. If the policyholder dies at this date, there is nothing left in the bequest from the insurance company. If the policyholder enters the LTC state, he then receives an annuity.

The Euler equation on consumption is not modified by the addition of LTC risk and insurance in Yaari's model if the utility function in the LTC state is the same as in good health. However, this equation holds only when the positivity constraint on wealth is not binding. As the income equations are different in the two models, the link between consumption and savings is also different. Lastly, the optimal timing of LTC insurance purchase is given by a "smooth pasting" condition on the residual expected utility of consumption and bequests. This means that a rational consumer should buy the insurance coverage at a date when the marginal value of waiting to purchase is equal to the marginal time value after the insurance purchase.

As an example, let us apply our life cycle model with a cost of LTC free of public benefits that is equal to two-thirds of the retirement income. We also assume that the insurance policy completely covers this loss and that the utility of consumption is the same in the LTC state as in good health. The occurrence and duration risks of LTC are derived from the statistical analysis of the preceding section. We suppose that the insurance policy is priced based on the expected loss, with the interest rate used for the consumer's utility, and with a loading factor equal to 30 per cent. We also included a 3-year qualifying period (i.e. the policyholder is insured if the LTC spell begins at least 3 years after the inception of the contract). With these assumptions, LTC insurance coverage is bought at 39 years, with a premium level equal to 0.6 per cent of the maximum income. The saving behaviour is close to what is observed without insurance, with the same ages for the wealth accumulation and decumulation cycle.

We now perform a sensitivity analysis of the consumer's behaviour with respect to the main parameters. These parameters are the subjective discount rate $a$, the intertemporal elasticity of substitution $\eta_{u}(c)=-u^{\prime}(c) / c u^{\prime \prime}(c)$ (inverse of the relative risk aversion for a separable lifetime utility, hence a constant for a CRRA utility function), the real interest rate $r$, the income flow and the coverage level $c l$ of LTC risk. Parameters are modified one by one, and the main results (interval where savings are

Table 2 Sensitivity analysis of the consumer's behaviour with respect to the main parameters: $a=3$ per cent; $\eta_{u}=1 / 2 ; r=2$ per cent; $c l=100$ per cent

\begin{tabular}{lcccc}
\hline $\begin{array}{l}\text { Departure }(s) \text { from } \\
\text { the basic scenario }\end{array}$ & $\begin{array}{c}\text { Beginning of the } \\
\text { saving period }\end{array}$ & $\begin{array}{c}\text { End of the } \\
\text { saving period }\end{array}$ & $\begin{array}{c}\text { Maximum } \\
\text { wealth }\end{array}$ & $\begin{array}{c}\text { Age at } \\
\text { purchase }\end{array}$ \\
\hline None & 41 & 84 & 2.52 & 39 \\
$\begin{array}{l}a=4 \% \\
\eta_{u}=1 / 3\end{array}$ & 45 & 81 & 1.65 & 42 \\
$r=3 \%$ & 40 & 87 & 2.79 & 37 \\
Other income flow & 38 & 91 & 3.86 & 36 \\
$c l=50 \%$ & 47 & 85 & 2.39 & 44 \\
\hline
\end{tabular}


positive, maximum wealth and age at insurance purchase) are given for each scenario in Table 2.

Let us briefly comment on these results. The maximum wealth is always reached at retirement, due to the drop in income at that date. The saving and insurance purchase decision is deferred if the subjective discount rate increases from 3 to 4 per cent, which is not surprising because preference for present increases then. The saving level strongly decreases and Yaari's model cannot match real-world behaviour for large values of the subjective discount rate. If relative risk aversion increases from 2 to 3 (hence $\eta_{u}$ decreases from $\frac{1}{2}$ to $\frac{1}{3}$ ), the saving period is wider and the purchase date decreases. The optimal consumption flow must be flatter since the intertemporal elasticity of substitution decreases, which explains the modification of the saving period. An increase in the real interest rate entails a modification of the output at the opposite of that observed after an increase in the subjective discount rate. In the latter case, the savings modification is similar whereas in the former case the increase in wealth is partly due to the modification of the rate of return on assets. The alternative income flow increases until retirement. The saving decision is delayed because highest income levels are reached later in the life cycle. Lastly, a partial insurance coverage does not modify the saving period, but increases slightly the saving level. Savings can be seen here as a substitute for insurance. Insurance purchase always precedes the beginning of the saving cycle in our examples, and the lag ranges between 2 and 4 years. Interpreting this result is not easy because the "smooth pasting" condition that determines the optimal purchase date is based on time derivatives of the residual lifetime utility. The meaning of those items is not easy to grasp.

Let us compare this life cycle approach with usual models of insurance demand. In our model, self-insurance means that the purchase decision is postponed until the end of the life cycle. A pending question is whether self-insurance with respect to LTC occurrence risk together with a saving cycle (very frequent in the real world) could be derived from this life cycle model. This might not be true, but assumptions of the Yaari's model favour an early purchase of LTC insurance. For instance, the income flow and the asset return are deterministic in Yaari's model and so is the optimal wealth path. In a risky environment, the consumer would value information on his wealth perspectives and postpone the purchase decision.

\section{Conclusions}

This paper presented the motivations for LTC insurance purchase. Occurrence and duration risks were estimated on a Spanish portfolio of permanent disability insurance contracts that are very similar to LTC products, and we also used national statistics on death rates. These results provide information on the magnitude of LTC risk. The role of LTC insurance contracts is twofold. First they provide hedging with respect to: (a) the occurrence risk of LTC spells, (b) the duration risk of such a spell and (c) the severity of dependency if the contract follows a reimbursement approach. Second, the coverage of this risk is funded, unlike the public coverage which is most often unfunded. Then we presented an economic model of optimal insurance purchasing in 
order to question the timing of LTC insurance purchase during a lifetime. The life cycle model deals with the transition and duration risks associated with the health states. We restricted the interpretation to a numerical application of the model and to a sensitivity analysis, but we plan to develop later an analysis of the purchase date as a function of the various parameters. We also intend to include ex post LTC insurance in the model. The purpose is to assess to what extent it could be a substitute to the classical insurance.

\section{Acknowledgements}

Jean Pinquet acknowledges financial support from the AXA chair "Large Risks in Insurance." Montserrat Guillen acknowledges financial support from the Spanish Ministry of Education and from Science FEDER. We thank the Fédération Française des Sociétés d'Assurance for providing us with valuable information.

\section{References}

Barsky, R.B., Juster, F.T., Kimball, M.S. and Shapiro, M.D. (1997) 'Preference parameters and behavioral heterogeneity: An experimental approach in the health and retirement study', Quarterly Journal of Economics 112: 537-579.

Bolin, K., Lindgren, B. and Lundborg, P. (2008) 'Informal and formal care among single-living elderly in Europe', Health Economics, forthcoming.

Brown, J. and Finkelstein, A. (2007) 'Why is the market for long-term care insurance so small?', Journal of Public Economics 91: 1967-1991.

Costa-Font, J. and Font-Vilalta, M. (2006) 'Design limitations of long-term care insurance schemes: A comparative study of the situation in Spain', International Social Security Review 59: 91-110.

Davidoff, T. (2008) Illiquid housing as self-insurance: The case of long-term care, working paper, Haas School of Business, Berkeley, CA.

De Meza, D. and Webb, D.C. (2001) 'Advantageous selection in insurance markets', Rand Journal of Economics 32: 249-262.

Fang, H., Keane, M.P. and Silverman, D. (2008) 'Sources of advantageous selection: Evidence from the Medigap insurance market', Journal of Political Economy 116: 303-350.

Finkelstein, A. and McGarry, K. (2006) 'Multiple dimensions of private information: Evidence from the long-term care insurance market', American Economic Review 96: 938-958.

Gollier, C. (2001) The Economics of Risk and Time, Hong Kong: MIT Press.

Gupta, A. and Li, L. (2007) 'Integrating long-term care insurance purchase decisions with saving and investment for retirement', Insurance: Mathematics and Economics 41: 362-381.

Kessler, D. (2008) 'The long-term care insurance market', The Geneva Papers on Risk and Insurance - Issues and Practice 33: 33-40.

Kunreuther, H., Ginsberg, R., Miller, L., Sagi, P., Slovic, P., Borkan, B. and Katz, N. (1978) Disaster Insurance Protections: Public Policy Lessons, Hoboken, NJ: Wiley Interscience.

Lee, R.D. and Carter, L. (1992) 'Modelling and forecasting the time series of US mortality', Journal of the American Statistical Association 87: 659-671.

Leung, S.F. (1994) 'Uncertain lifetime, the theory of the consumer, and the life cycle hypothesis', Econometrica 62: 1233-1239.

Merton, R.C. (1969) 'Lifetime portfolio selection under uncertainty: The continuous-time case', The Review of Economics and Statistics 51: 247-257.

Pauly, M. (1990) 'The rational nonpurchase of long-term care insurance', Journal of Political Economy 98 : 153-168.

Samuelson, P.A. (1969) 'Lifetime portfolio selection by dynamic stochastic programming', The Review of Economics and Statistics 51: 239-246.

Sloan, F.A. and Norton, E.C. (1997) 'Adverse selection, moral hazard, crowding out, and private demand for insurance: Evidence from the long-term care insurance market', Journal of Risk and Uncertainty 15: 201-219. 
Taleyson, L. (2003) 'Private long-term care insurance - international comparisons', The Geneva Association, Health and Ageing Newsletter 8: 8-11.

Van Houtven, C.H. and Norton, E.C. (2004) 'Informal care and health care use of older adults', Journal of Health Economics 23: 1159-1180.

Yaari, M. (1965) 'Uncertain lifetime, life insurance, and the theory of the consumer', The Review of Economics Studies 32: 137-150.

\begin{abstract}
About the Authors
Montserrat Guillén is full professor of econometrics at the University of Barcelona, Spain, where she obtained her PhD in Economics and her MSc in Mathematics. She received an MA in Data Analysis from the University of Essex, U.K. She is currently the director of the research group Risk in Insurance and Finance at IREA, University of Barcelona. She is an associate editor of The Journal of Risk and Insurance.

Jean Pinquet is a graduate of ENS Cachan and ENSAE, with a qualified professorship (agrégé) in mathematics. He is also a qualified actuary. He teaches at University Paris $\mathrm{X}$ and is a research associate of the Ecole Polytechnique (department of economics), where he is sponsored by the AXA chair "large risks in insurance." He is a co-editor of The Journal of Risk and Insurance.
\end{abstract}

